\title{
SChinus Sección Myrtifolia (Anacardiaceae) en Argentina
}

\author{
Schinus section Myrtifolia (Anacardiaceae) in Argentina
}

\author{
Evangelina C. Lozano ${ }^{1} \odot$, María A. Zapater ${ }^{1} \odot$, Carolina B. Flores ${ }^{1} \odot$ \& Víctor H. Aquino ${ }^{1} \odot$
}

\begin{abstract}
Resumen: Schinus es un género muy conocido, ecológica y económicamente importante en Argentina. Un estudio filogenético molecular reciente propuso una nueva clasificación infragenérica de Schinus en secciones. La sección Myrtifolia se ha definido como un clado de ca. 11 especies de las Yungas, cinco de las cuales se encuentran en Argentina (S. gracilipes, S. huyngan var. subtridentata, S. meyeri, S. myrtifolia y S. venturii). El objetivo de este trabajo fue presentar una síntesis actualizada de la diversidad de Schinus sección Myrtifolia en Argentina. Se revisaron y realizaron nuevas colecciones. La metodología fue la tradicional de estudios taxonómicos, con observaciones morfológicas. Se analizaron protólogos, tipos y se registraron distribuciones geográficas. Nuestros resultados apoyan la existencia de solo cuatro especies en Argentina, porque proponemos la sinonimia de S. meyeri con S. venturii y de S. gracilipes var. pilosa con S. gracilipes. Schinus huyngan var. subtridentata es una nueva cita. Se presenta un mapa de distribución de las cuatro especies y una clave taxonómica. Schinus gracilipes y $S$. huyngan var. subtridentata son las especies más fáciles de identificar; S. myrtifolia y S. venturii muestran la mayor variación morfológica foliar. Las especies se diferencian entre sí por su distribución latitudinal.
\end{abstract}

Palabras clave: Novedades taxonómicas, Schinus gracilipes, S. huyngan var. subtridentata, $S$. myrtifolia, S. venturii, Yungas australes.

\begin{abstract}
Summary: Schinus is a well known ecologically and economically important genus in Argentina. A recent molecular phylogenetic study proposed a new infrageneric classification of Schinus in sections. Section Myrtifolia has been defined as a clade of ca. 11 species from the Yungas, five of which occurring in Argentina (S. gracilipes, S. huyngan var. subtridentata, S. meyeri, S. myrtifolia, and $S$. venturii). The objective of this work was to present an updated synthesis of the diversity of Schinus section Myrtifolia in Argentina. New collections were revised and made. The traditional methodology for taxonomic studies, including morphological observations, was followed. Protologues and types were analyzed, and geographic distributions were recorded. Our results support the existence of only four species in Argentina, because we propose the synonymy of S. meyeri with S. venturii and of S. gracilipes var. pilosa with S. gracilipes. Schinus huyngan var. subtridentata is a new mention. A distribution map of the four species and a taxonomic key are presented. Schinus gracilipes and S. huyngan var. subtridentata are the most easily identified species; S. myrtifolia and S. venturii show the highest leaf morphological variation. Species are differentiated from one another by their latitudinal distribution.
\end{abstract}

Key words: Taxonomic novelties, Schinus gracilipes, S. huyngan var. subtridentata, S. myrtifolia, S. venturii, southern Yungas.

\footnotetext{
${ }^{1}$ Facultad de Ciencias Naturales, Universidad Nacional de Salta, Avda. Bolivia 5150, 4400 Salta, Argentina. E-mail: evangelozano@gmail.com
} 


\section{Introducción}

En la sección Pseudoduvana F. A. Barkley, fueron citadas cuatro especies para Argentina: Schinus myrtifolia (Griseb.) Cabrera, Schinus venturii F. A. Barkley, Schinus gracilipes I. M. Johnst. y Schinus patagonicus (Phil.) I. M. Johnst., las tres primeras con distribución en el NOA (noroeste argentino) y la cuarta en el sur del país (Barkley, 1957). Posteriormente, Barkley (1973) citó una nueva especie para Argentina y Bolivia en esta sección, Schinus meyeri F. A. Barkley.

Silva-Luz et al. (2019) realizó un estudio filogenético para el género proponiendo una nueva clasificación seccional; así las especies de la sect. Pseudoduvaua fueron reubicadas en la sect. Myrtifolia. Esta sección es un clado notable de hojas simples con muchas semejanzas por lo que sus taxa fueron confundidas y mal determinadas; por otra parte, presentan polimorfismo foliar en un mismo individuo y entre los de una misma población. Los taxones de esta sección citados en la literatura para Argentina son: $S$. gracilipes var. gracilipes, $S$. gracilipes var. pilosa F. A. Barkley, S. meyeri, S. myrtifolia y $S$. venturii (Silva-Luz et al., 2019), y se agrega aquí a $S$. huyngan var. subtridentata Kuntze, nueva cita para el país.

En este trabajo se estudiaron detalladamente un elevado número de ejemplares de la sección Myrtifolia de las Yungas de Argentina, en su variación morfológica, en la búsqueda de caracteres diferenciales entre los taxones.

\section{Materiales y Métodos}

Se estudiaron las colecciones de los herbarios CORD, CTES, LIL, LP, MCNS y SI (abreviaturas según Thiers, 2021); también se consultaron los ejemplares digitalizados de los herbarios Field Museum of Natural History, Chicago (F); Harvard University Herbarium(GH); Herbarium Göttingen (GOET); Missouri Botanical Garden (MO); The William and Lynda Steere Herbarium of the New York Botanical Garden (NY); Swedish Museum of Natural History (S); Instituto de Botánica de San Pablo (SP); y United States National Herbarium (US), disponibles en la página electrónica de TROPICOS (TROPICOS, 2021) y JSTOR Global Plants (JSTOR, 2021). Se revisaron protólogos y se efectuaron colecciones en diferentes ambientes realizando descripciones completas de todos los órganos; se registraron los sitios de colecta, las características del hábitat y la fenología. Las abundantes agallas presentes en las ramas de $S$. myrtifolia y $S$. venturii, fueron estudiadas y el agente que las produce determinado por el Dr. J. Corronca, profesor de Entomología de la Universidad Nacional de Salta (2018). Se analizaron las distribuciones y se confeccionó un mapa. Se elaboró una clave para la identificación de las especies.

\section{Resultados}

1. Schinus gracilipes I. M. Johnst., J. Arnold Arb. 19: 257-258. 1938. Typus: Argentina. Tucumán: Dep. Trancas, Tapia, 29-VIII1925, Venturi 3887 (holotypus GH00049175!; isotypi LIL000748, LP011028!, MO260753!, SI000726!) Fig. 1A-N.

Schinus gracilipes var. pilosa F. A. Barkley, Brittonia 5(2): 180. 1944. Typus: Argentina. Tucumán: Dep. Trancas, pie de la cuesta o Yuchayo, $1.700 \mathrm{~m}, 19-\mathrm{IV}-1926$, Venturi 4173 (holotypus US1590089-00095716!; isotypi LIL000749!, LP011021!). Syn nov.

Árbol (raro) o arbustos diclino-dioicos, perennifolios, de 2-5 m alt. Corteza oscura finamente reticulada. Ramas grisáceas, a veces densamente pubescentes, con lenticelas irregulares de 0,05-1,2 mm diám., esparcidas, anaranjadas. Hojas de 3,6-10 × 1,7-3,3 cm, ovadas u ovado-lanceoladas, subcartáceas; ápice redondeado, a veces agudo o retuso; base levemente oblicua, cuneada, decurrente, a veces redondeada; margen delgado translúcido revoluto, crenado o crenado-aserrado regular o irregular, excepto en la base que es entera; discoloras; con 8-17 pares de nervios secundarios subparalelos notables, irregulares, nervios de tercer orden bien perceptibles; pubescentes en el haz, semidensa en los márgenes del nervio principal $\mathrm{y}$ en la base 
de la lámina, rala en el resto de la lámina con pequeños tricomas glandulares, envés con tricomas glandulares pequeños esparcidos; pecíolo de 5-17 $\mathrm{mm}$ long., canaliculado, ventralmente con tricomas glandulares ralos y dorsalmente con pubescencia corta densa. Inflorescencias con brácteas de 0,6-1 × 0,5$0,6 \mathrm{~mm}$, ovadas, cóncavas con el nervio medio visible, pubescencia hírtula muy corta semidensa; bractéolas de 0,2-0,3 $\times$ 0,14-0,3 mm ovadas con ápice redondeado, idéntica pubescencia a la bráctea. Tirsoide estaminado de 8-30 mm long., con 35-50 flores, raquis a veces con ramificaciones en cada nudo y generalmente tres flores en los nudos, puberulento a densamente velloso. Flores estaminadas con sépalos de 0,8-1 $\times$ 0,9-1,3 mm, deltoides, márgenes ciliados, pubescentes a densamente vellosos en el dorso; pétalos de 1,8-2 × 1,1-1,5 mm, ovados, ligeramente cóncavos, ciliados en el margen; disco interestaminal lobulado; androceo con 8 estambres en 2 ciclos, el externo de 1-1,1 $\mathrm{mm}$ long. y el interno de 0,7-0,9 mm long. incluida la antera, filamentos aplanados y ensanchados hacia la base, anteras de 0,3-0,4 mm long.; pistilodio de 0,3-0,4 × 0,25-0,3 $\mathrm{mm}$, piriforme, con 3 ramas estilares erectas; pedicelo articulado de 2,5-4 $\mathrm{mm}$ long. con extremo apical acopado, pubescencia desde corta semidensa a larga y densa, con disco de abscisión. Tirsoides o pseudoracimos pistilados de 8-15 mm long. con 8-15 flores; raquis no ramificado, puberulento a densamente velloso. Flores pistiladas con sépalos de 0,5-1,2 $\times$ 0,8-1 mm, deltoides, pilosos a densamente vellosos en el dorso; pétalos de 1,3-1,7 ×0,7-1 $\mathrm{mm}$, ovados $\mathbf{u}$ oblongos, cóncavos, márgenes ciliados; disco interestaminal lobulado; estaminodios de 0,3-0,4 mm long. incluidas las anteras de 0,2-0,25 mm long.; gineceo de $1,1-1,5 \times 0,8-1,1 \mathrm{~mm}$, ovario globoso con pequeños tricomas glandulares, estilo único corto de 0,1-0,2 mm, apicalmente trivergente erecto, a la madurez horizontal y oscuro, de 0,3-0,5 mm incluidas las cabezas estigmáticas discoidales subcapitadas; pedicelo articulado de 2,5-4 $\mathrm{mm}$ con extremo apical acopado, pubescencia desde corta semidensa a larga y densa, con disco de abscisión. Fruto drupa de 4,6-7,8 $\times$ 5-8 $\mathrm{mm}$, grosor $2-5 \mathrm{~mm}$, rojiza, ovoidea, lateralmente comprimida; cáliz y pedicelo superior excéntrico, persistente; exocarpo friable, rojizo con papilas esparcidas; mesocarpo externamente rugoso, castaño, con conductos resiníferos de 0,19-0,26 mm diám.; endocarpo de 0,08-0,11 mm lat. con una capa de macroesclereidas y otra de braquiesclereidas en empalizada. Semilla amarilla eliposoide de $3-3,5 \times 1-1,2 \mathrm{~mm}$.

Nombres vulgares: "Molle", "molle del cerro", "molle de la quebrada", "horcomolle".

Fenología: La floración se produce de agosto a marzo. Se encuentran frutos maduros desde enero hasta marzo-abril. Según Digilio y Legname (1966), en Tucumán florece de agosto a noviembre y fructifica de diciembre a febrero.

Distribución geográfica y ecológica: Endémica del noroeste argentino, se distribuye desde el sur de Salta donde es escasa, hasta Tucumán y norte de Catamarca, con abundantes poblaciones en la provincia de Tucumán (Fig. 7). Las poblaciones de $S$. gracilipes son arbustivas, raro con aspecto de arbolito, los que se pueden encontrar en laderas pronunciadas, rocosas, montañas umbrías y húmedas, en el Bosque Montano de Yungas, asociados con los bosques de Alnus acuminata Kunth, Podocarpus parlatorei Pilg., Polylepis australis Bitter y $P$. hieronymi Pilg., también en praderas andinas, entre $1.000-2.500 \mathrm{~m}$.

Según Perea et al. (2007) en Catamarca se la observó creciendo en laderas bien iluminadas con orientación este. Estos autores la mencionan como habitante común de las quebradas en el Cerro Ambato por encima del bosque de pinos (Podocarpus parlatorei) aunque suele verse mezclada con éste en la parte más joven del pinar. Según los autores el área de dispersión comprende las laderas este de Ambato entre los 1.500-2.500 m.

\section{Material estudiado: ARGENTINA.}

Catamarca: Dep. Ambato, La Junta, 1918, fr., Jörgensen $991 b$ (SI033334). Dep. Andalgalá, El Candado, $2.700 \mathrm{~m}, 24-X I I-1915$, fr., Jörgensen 991a (LIL, SI033333). Salta: Dep. Guachipas, Cuesta El Lajar, Ruta 9, 23 km al 
SE de Guachipas, 1.900-2.000 m, 16-I-1990, fl., Novara \& Bruno 9393 (MCNS). Dep. La Candelaria, Sierra de la Candelaria, $1.700 \mathrm{~m}$, 23-IX-1929, fl., Venturi 957I (SI 033340).

Tucumán: Dep. Burruyaco, de Río Nio al Alto de Medina 8 km, 1.500 m, 16-IX-1961, fl., Villa Carenzo et al. 1671 (LIL). Dep. Chicligasta, río Cochuna, 3-XI-1930, fl., Schreiter 6461 (LIL). Dep. Monteros, quebrada de los Soria, 11-XII-1958, fl., Morello et al. s.n. (LIL). Dep. Tafi del Valle, la curva, ladera rocosa, umbría y húmeda, 15-II-2019, Lozano et al. 1621 (MCNS); Tafí del Valle, ciudad de Tafí, calle Los Menhires, en cerco vivo, 15-II-2019, Lozano et al. 1646 (MCNS); El Mollar, en entrada pasando rotonda hacia el pueblo, 21 I-2020, Lozano et al. 1843 (MCNS); saliendo hacia Amaicha a $5 \mathrm{~km}$ de Tafí, 23-I-2020, Lozano et al. 1890 (MCNS). Dep. Tafí Viejo, quebrada de La Hoyada a la Cuesta de Los Bravos, 1.600 m, 30-IX-1924, fl., Schreiter 3312 (LIL). Dep. Trancas, pasando San Pedro de Colalao, cuesta del Hualinchay, 2.500 m, 10-IV-1914, fl., Rodríguez 29 a, b, c (SI033328, SI033329, SI033330). Dep. Yerba Buena, San Javier, pasando Cristo Redentor, costado camino por RP 340 hacia Tapia, 16-II2019, Lozano et al. 1673 (MCNS).

Observaciones: 1- Barkley (1944) describió S. gracilipes var. pilosa basado en especímenes cuyas ramas, hojas e inflorescencias son densamente pubescentes. El análisis morfológico de la especie evidenció que $S$. gracilipes tiene pubescencia variada desde glabra hasta densamente pubescente (lo que es menos frecuente), por lo que se considera que la var. pilosa es un sinónimo, concordante con lo expresado por Muñoz (2000).

2- Según el lugar donde se encuentre la planta, el porte es variable desde pequeño árbol hasta arbusto medio o bajo; además de la forma, tamaño y consistencia de las hojas, dependiente del grado de humedad e insolación.

3- La inflorescencia estaminada es siempre más larga, de 12-28 mm long., también más compleja y con mayor número de flores (pluriflora) que la pistilada de 0,7-10 mm long., siendo las inflorescencias axilares muy cortas y paucifloras, las apicales son largas y plurifloras.
Los pétalos de las flores estaminadas son más grandes de 1,9-2 × 1,1-1,2 mm, versus los pétalos de la flor pistilada de 1,4-1,5 × 0,9-1 $\mathrm{mm}$. Los pedicelos también son variables, siendo el estaminado más corto de 1,2-3,3 mm long. y el pistilado de $2-4,5 \mathrm{~mm}$ long.

4- Schinus gracilipes tiene un hábitat típicamente yungueño restringido a la parte superior de la Selva montana en ecotono con el Bosque montano, en el Bosque montano y en los Pastizales de neblina o Praderas andinas en áreas de bajas latitudes. Para Muñoz (2000) $S$. gracilipes habita además en zonas del Chaco. Digilio et Legname (1966) mencionan que también se encuentra en el Monte. Estos tres autores la sitúan habitando en la provincia de Jujuy. Estas distribuciones no se pudieron comprobar durante la ejecución de este trabajo. Según Silva-Luz (2017), S. gracilipes se encuentra en ecotonos entre bosques nubosos montanos y no se pudo comprobar la presencia en áreas áridas y semiáridas como Prepuna, Puna, valles secos interandinos o Chaco; también menciona que puede coexistir con $S$. areira L., $S$. bumelioides I. M. Johnst. y $S$. pilifera I. M. Johnst., situación no detectada en Argentina porque estas especies tienen otros hábitats.

5- Respecto al lugar de colección del tipo de $S$. gracilipes, se detectó una incongruencia en el registro del sitio de colecta debido a que la localidad de Tapia $(750 \mathrm{~m})$ en Tucumán se encuentra en un área de Chaco serrano seco, donde es abundante otra especie del género (Schinus pilifera), no habiéndose encontrado población alguna de $S$. gracilipes y siendo altamente improbable su presencia a una altitud tan baja. Por ello se infiere que el colector Venturi debió haberse confundido al registrar la localidad de la colecta, quizás eventualmente anotó el inicio de la Ruta Provincial 341 en la localidad de Tapia y que ascendió por la misma a las serranías altas del este donde pudo quizás efectuar esta colección.

6- Durante la realización de este estudio se encontraron varios ejemplares de herbario de $S$. myrtifolia confundidos (mal determinados) como $S$. gracilipes, debido a que la primera especie también puede presentar en algunos individuos hojas con borde totalmente crenado o solo en algunas ramas. 

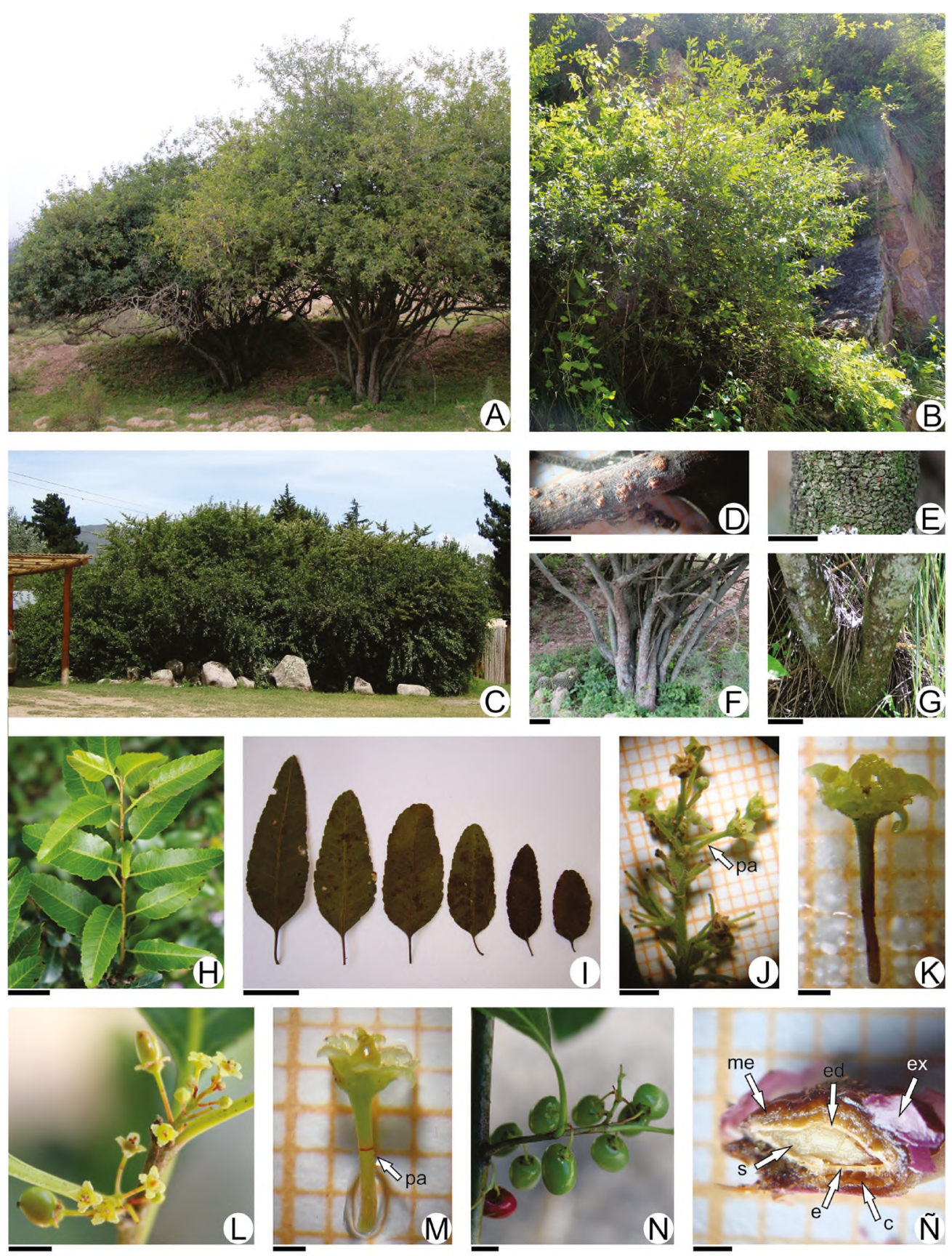

Fig. 1. Schinus gracilipes. A-B: Planta en su ambiente natural. C: Planta cultivada. D: Rama con lenticelas. E: Corteza. F-G: Tallo. H-I: Hojas. J: Inflorescencia estaminada. K: Flor estaminada. L: Inflorescencia pistilada. M: Flor pistilada. $\mathrm{N}$ : Rama con frutos. Ñ: Corte transversal de fruto. Referencias: c: canal resinifero, e: empalizada, ed: endocarpo, ex: exocarpo, me: mesocarpo, pa: pedicelo articulado, s: semilla. Escala: D-J-L-N: $3 \mathrm{~mm}$; E: $10 \mathrm{~cm} ; \mathrm{F}: 30 \mathrm{~cm}$; G: $20 \mathrm{~cm}$; H-I: $3 \mathrm{~cm}$; K-M-Ñ: $1 \mathrm{~mm}$.

Fig. 1. Schimus gracilipes. A-B: Plant in its natural environment. C: Cultivated plant. D: Branch with lenticels. E: Bark. F-G: Stem. H-I: Leaves. J: Staminate inflorescence. K: Staminate flower. L: Pistillate inflorescence. M: Pistillate flower $\mathrm{N}$ : Branch with fruits. $\tilde{\mathrm{N}}$ : Cross section of fruit. References: c: resin canal, e: palisade, ed: endocarp, ex: exocarp, me: mesocarp, pa: articulated pedicel, s: seed. Scale: D-J-L-N: 3 mm; E: $10 \mathrm{~cm}$ F: $30 \mathrm{~cm}$; G: $20 \mathrm{~cm}$; H-I: $3 \mathrm{~cm}$; K-M-Ñ: $1 \mathrm{~mm}$. 
7- El holotipo de $S$. gracilipes (Venturi 3887) depositado en $\mathrm{GH}$, es un ejemplar con tres ramas, la rama central posee frutos, abundantes hojas e inflorescencias pistiladas, las dos ramas laterales son estaminadas con abundantes inflorescencias axilares. Como la especie es diclino-dioica, este ejemplar es una mezcla de al menos dos individuos.

\section{Schinus huyngan Kuntze var. subtridentata} Kuntze, Revis. Gen. P1. 3(3): 46. 1898. Fig. 2A-I.

Schinus andina (Engl.) I. M. Johnst. var. subtridentata (Kuntze) F. A. Barkley, Brittonia 5(2): 179. 1944. Typus: Bolivia. Cochabamba, 26 marzo 1892, Kuntze s.n. (syntypus NY000050894!)

Arbusto diclino-dioico, hasta de $2 \mathrm{~m}$ alt. Corteza marrón. Ramas con extremo delgado subagudo, regularmente estriadas, pardo rojizas brillantes; lenticelas elevadas regulares de 0,5 mm diám., esparcidas, cobrizas; pubescencia glandular semidensa. Hojas de 1,17-2,49 × 0,55$1,13 \mathrm{~cm}$, obovadas raro elípticas, coriáceas; ápice obtuso redondeado, base cuneada decurrente; margen engrosado, ocráceo, revoluto, 3-5 crenado en el tercio o mitad apical, con margen entero en la base; discoloras; con 3(-6) pares de nervios secundarios paralelos notables; en el haz nervio principal con pubescencia corta semidensa en la mitad basal y escasos tricomas glandulares, envés glabro; pecíolo de 1-2,82 mm long., ventralmente con pubescencia corta, hírtula, glabro dorsalmente. Inflorescencias con brácteas de 0,6-0,7 × 0,8-0,9 mm, deltoides, nervio medio marcado, pubescencia hírtula en el dorso y cilios en los márgenes. Pseudoracimo estaminado plurifloro, congesto, de 7,64-11,63 mm long., raquis anguloso con pubescencia glandular esparcida, sobre un pequeño braquiblasto. Flores estaminadas con sépalos de $0,7-0,9 \times 0,6-0,8 \mathrm{~mm}$, triangulares, con ápice caudado, a veces apiculado, nervio medio notable en el envés, margenes ciliados; pétalos de 1,1-1,25 × 0,68-0,80 mm, obovadooblongos a redondeados, margen irregularmente ondulado, glabro; disco interestaminal lobulado; androceo con 8 estambres en 2 ciclos, el ciclo externo de $0,9 \mathrm{~mm}$ long. y el interno de $0,6 \mathrm{~mm}$ long. incluida la antera, filamentos aplanados y ensanchados hacia la base, anteras de $0,3 \times 0,3$ $\mathrm{mm}$; pistilodio de $0,4 \times 0,25 \mathrm{~mm}$, cilíndrico, con 3 ramas estilares gruesas trivergentes; pedicelo articulado de 1,55-3,5 $\mathrm{mm}$ long. con extremo apical acopado, pubescente semidenso con tricomas glandulares, con disco de abscisión prominente. Pseudoracimo pistilado laxo paucifloro de 3,42-5,06 mm long.; raquis anguloso con pubescencia glandular esparcida. Flores pistiladas con sépalos de 0,59-0,75 mm long., deltoides, subagudos, márgenes ciliados, pubescencia hírtula en el envés; corola dialipétala. Fruto drupa de 3,66,5 long. $\times 3,8-5 \mathrm{~mm}$, grosor $2-3 \mathrm{~mm}$, rojiza, ovoidea, lateralmente comprimida, cáliz y estilo excéntricos, persistentes; exocarpo friable, rojizo con tricomas en formas de pelos y papilas esparcidos; mesocarpo externamente rugoso, castaño oscuro, con conductos resiníferos de 0,5-1,5 mm diám.; endocarpo de 0,24-0,3 mm lat., ondulado, constituido por una capa de macroesclereidas y otra de braquiesclereidas en empalizada. Semilla amarilla fusiforme de $3 \times$ $0,5 \mathrm{~mm}$.

Nombres vulgares: "Chirimolle" (español); "huislulu", "suilulu", "sip'I nuko", "wislulu" (quichua) (Silva-Luz, 2017).

Fenología: Probable floración desde agosto hasta diciembre y fructificación desde diciembre a marzo.

Distribución geográfica y ecológica. Según Silva-Luz (2017), la especie se distribuye en Bolivia en los departamentos de La Paz y Cochabamba, hacia el centro-sur en los departamentos de Chuquisaca y Potosí. A partir de esta investigación y con la mención de un ejemplar coleccionado en las Serranías de Calilegua (Jujuy), su distribución se extendería al sur hasta las Yungas Australes de Argentina en Jujuy, no habiendo registros en Salta (Fig. 7).

\section{Material adicional estudiado:} ARGENTINA. Jujuy: Dep. Valle Grande, serranías de Calilegua, Mesías, 18-II-1965, fr., Fabris et al. 5890 (LIL 500835). BOLIVIA.

Santa Cruz: Prov. Valle Grande, Samaipata, 2.000 m, 17-III-1920, fl., Steinbach 3789 (LIL). Chuquisaca: Comunidad Ovejero, 

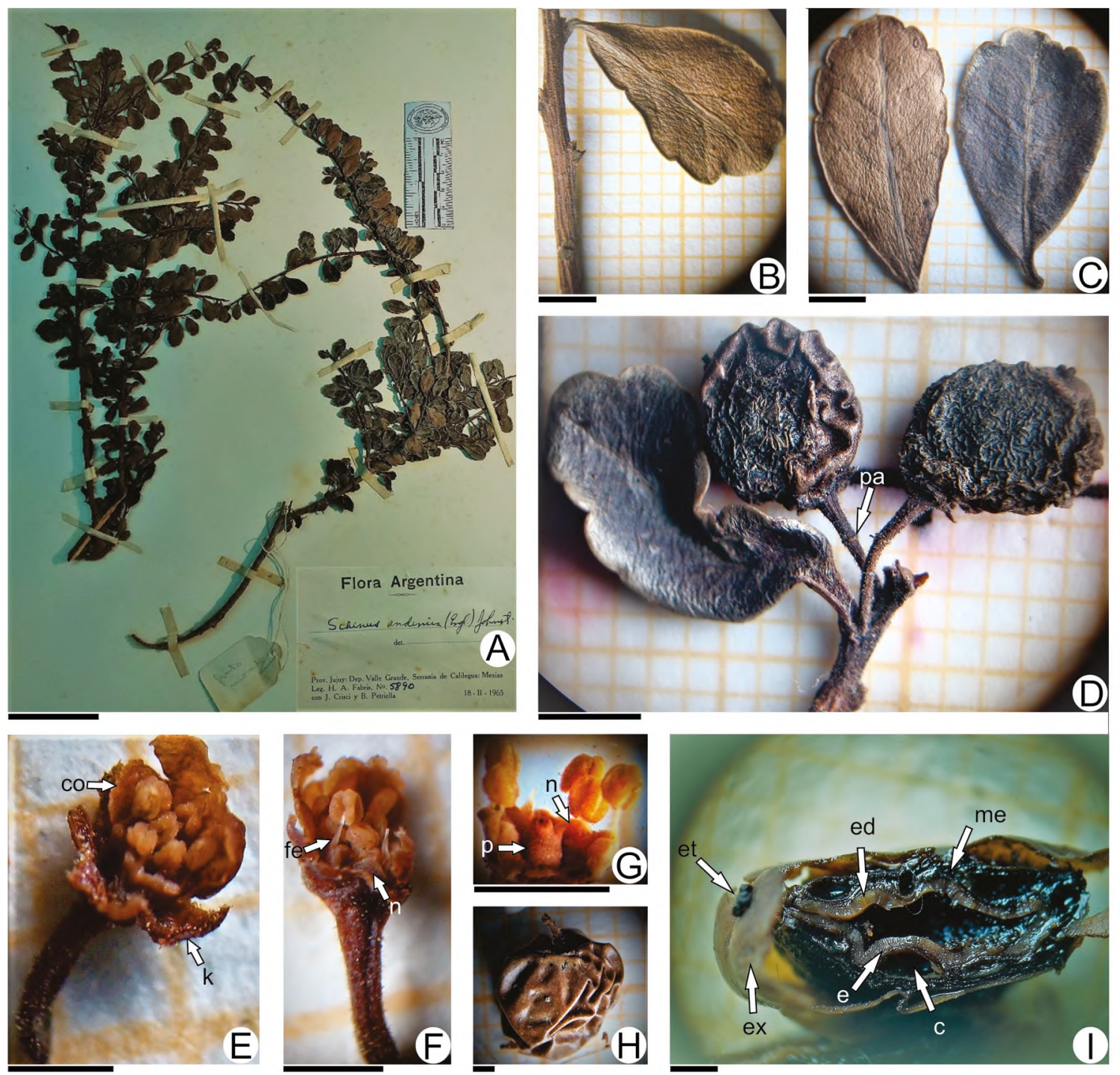

Fig. 2. Schinus huyngan var. subtridentata. A: Ejemplar de herbario (Fabris et al. 5890, LIL). B: Rama con hoja. C: Hoja. D: Rama con frutos. E: Flor estaminada (Muruaga et al. s.n., LIL608470). F-G: Detalle de flor estaminada. H: Fruto. I: Corte transversal de fruto. Referencias: c: canal resinífero, co: corola, e: empalizada, ed: endocarpo, et: estilo persistente, ex: exocarpo, fe: filamento estaminal con base ensanchada, $\mathrm{k}$ : cáliz, me: mesocarpo, n: lóbulos del disco nectarífero, pa: pedicelo articulado. Escala: A: $5 \mathrm{~cm}$; B-D: $3 \mathrm{~mm}$; E-I: $1 \mathrm{~mm}$.

Fig. 2. Schinus hurngan var, subtridentata. A: Herbarium specimen (Fabris et al. 5890, LIL). B: Branch with leaf. C: Sheet. D: Branch with fruits. E: Staminate flower (Muruaga et al. s.n., LIL608470). F-G: Detail of staminate flower. H: Fruit. I: Cross section of fruit. References: c: resin canal, co: corolla, e: palisade, ed: endocarp, et: persistent style, ex: exocarp, fe: staminal filament with widened base, $\mathrm{k}$ : calyx, me: mesocarp, n: lobes of nectariferous disc, pa: articulated pedicel. Scale: A: $5 \mathrm{~cm}$; B-D: $3 \mathrm{~mm}$; E-I: $1 \mathrm{~mm}$.

$2.300 \mathrm{~m}, 8-\mathrm{XII}-2006$, Muruaga et al. s.n. (LIL628470).

Observaciones: 1- En los estudios realizados en LIL, se encontró un espécimen con frutos determinado inicialmente como Schinus andina (Engl.) I. M. Johnst. (Fabris et al. 5890) y además otros dos ejemplares semejantes de Bolivia.

2- Según Barkley (1957), S. andina posee gran similitud con Schinus microphylla. 
Previamente Macbride (1951) para la Flora de Perú, había generado la combinación $S$. microphylla var. andina (Engl.) J. F. Macbr., considerando a $S$. andina como una variante de $S$. microphylla menos pubescente, con hojas coriáceas e inflorescencias más pequeñas.

3-Del análisis morfológico de los ejemplares de $S$. microphylla y $S$. andina, Silva-Luz (2017) identifica dos morfotipos basados principalmente en las características de las hojas $\mathrm{y}$ las inflorescencias. El primer morfotipo que reconoce como perteneciente a $S$. microphylla presenta ramas que terminan en espinas, que van desde llamativamente espinosas (ejemplares peruanos) a discretamente espinosas (ejemplares bolivianos), ramas y hojas con indumento estrigoso. El segundo morfotipo que reconoce como $S$. huyngan var. subtridentata posee ramas inermes o con espinescencia escasa, rama de extremo agudo no punzante, con indumento glandular claviforme.

4- Según Silva-Luz (2017), aunque la mayoríade losespecímenes fueron identificados como $S$. andina corresponden al segundo morfotipo, característico por sus ramas no espinescentes agudas, muy ramificadas, con cortos entrenudos, hojas coriáceas, pequeñas, obovadas, con ápice 3-5 lobulado y lámina triangular con base cuneada, margen revoluto y breve pecíolo canaliculado, como el caso del ejemplar Fabris 5890.

3. Schinus myrtifolia (Griseb.) Cabrera, Obr. Cincuent. Mus. La Plata 2: 269. 1937, como Cybianthus myrtifolius Griseb. en sinonimia, en Barkley, Lilloa 28: 61-62. 1957. Figs. 3A$\mathrm{O}, 4 \mathrm{~A}-\mathrm{E}$.

Cybianthus myrtifolius Griseb., Abh. Königl. Ges. Wiss. Göttingen 24: 222. 1879. Typus: Argentina. Yacone, "cerca de Salta", III1873, Lorentz \& Hieronymus 317 (lectotypus GOET020105, imagen Herb. GOET!, designado por F. Barkley 1957; isolectotypi CORD00004915!, LP 004398!)

Árbol o arbustos diclino-dioicos, caducifolios de 2-7 m alt. Corteza oscura, subrugosa. Ramas levemente estriadas, castaño oscuras, con lenticelas de $0,3-0,5$ $\mathrm{mm}$ diám., densas, cobrizas, pubescencia hírtula corta esparcida o semidensa y tricomas glandulares pequeños. Hojas de 1,3-7 × 0,8$2,9 \mathrm{~cm}$, polimórficas, obovadas, redondeadas, elípticas, raro oblongas, cartáceas a la madurez; ápice redondeado, a veces retuso o emarginado, raro agudo; base generalmente decurrente hasta cuneada, a veces suboblicua; margen delgado, translúcido y revoluto, generalmente entero, a veces irregularmente crenado en el extremo apical o hasta 1/2, a veces toda la lámina de algunas hojas o todas las hojas de un individuo; discoloras; 5-12 pares de nervios secundarios subparalelos, irregulares y verdosos; pubescencia en el haz muy corta, esparcida en la base del nervio principal y lámina, tricomas glandulares pequeños densos sobre nervio principal $y$ en los nervios laterales, en la base semidensos, irregularmente distribuidos en el resto de la lámina, envés con tricomas glandulares en margen y lámina; pecíolo de 2-7 mm long., canaliculado, con tricomas cortos semidensos y glandulares esparcidos más densos en el haz. Inflorescencias a veces en caulifloría, con brácteas de $0,8-1,1 \times 1,1-1,2 \mathrm{~mm}$, ovadas 0 deltoides con ápice redondeado, pubescencia pilosa muy corta principalmente en el dorso y cilios en los márgenes; bractéolas de $0,5-0,7 \times$ 0,3-0,4 mm, agudas, idéntica pubescencia a la bráctea. Pseudoracimo estaminado de 12-25 $\mathrm{mm}$ long. con 15-20 flores, raquis levemente anguloso, pubescencia pilosa esparcida a tomentosa. Flores estaminadas con sépalos de 0,9-1 × 1,1-1,2 mm, deltoides, márgenes ciliados, pubescencia pilosa corta rala en el dorso; pétalos de 1,9-2 × 1,1-1,2 mm, ovados, ápice redondeado, margen transparente ligeramente ondeado, brevemente reflexo en los costados, generalmente glabros a veces con tricomas glandulares esparcidos en el haz; disco interestaminal lobulado; androceo con 8 estambres en 2 ciclos, el externo de 1,2-1,3 $\mathrm{mm}$ long. y el interno de 0,9-1 $\mathrm{mm}$ long. incluida la antera, filamentos aplanados y ensanchados hacia la base, anteras de 0,4-0,5 mm long.; pistilodio de $0,4-0,5 \times 0,2-0,3 \mathrm{~mm}$, piriforme, con 3 ramas estilares erectas; pedicelo no articulado de 1,2-3,3 mm long. con extremo apical acopado, cortamente piloso. Pseudoracimos pistilados de 7-10 mm long., con 7-14 flores; raquis 

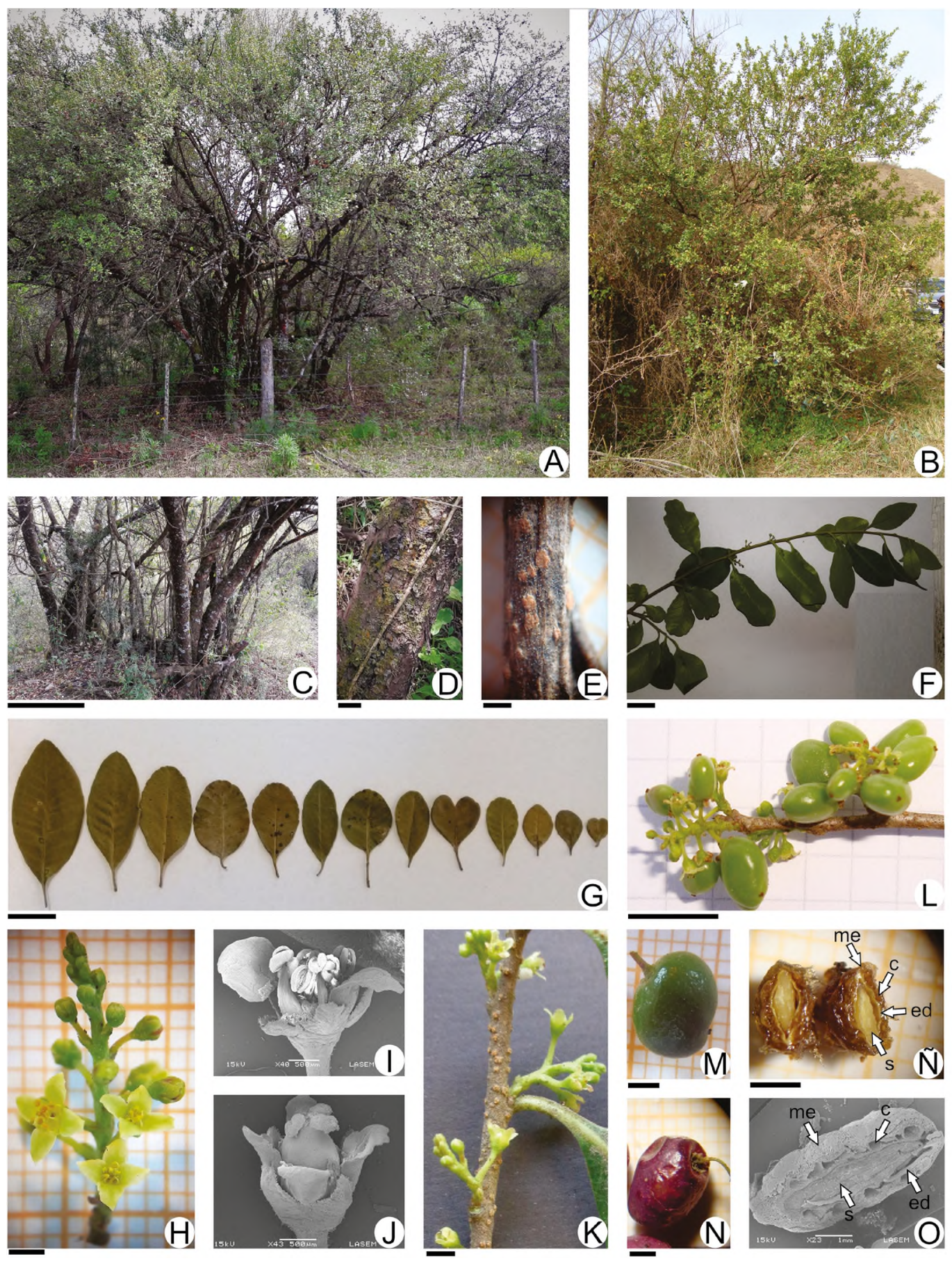

Fig. 3. Schinus myrtifolia. A-B: Planta en su ambiente. C: Tallos. D: Corteza. E: Rama con lenticelas. F-G: Hojas. H: Inflorescencia estaminada. I: Flor estaminada. J: Flor pistilada. K: Inflorescencia pistilada. L: Rama con frutos. M-N: Frutos. Ñ-O: Corte transversal del fruto al MO y MEB. Referencias: c: canal resinífero, ed: endocarpo, me: mesocarpo, s: semilla. Escala: C: $1 \mathrm{~m}$; D: $5 \mathrm{~cm}$; F-G: $2 \mathrm{~cm}$; H, M-Ñ: $2 \mathrm{~mm}$; K: $1 \mathrm{~mm}$.

Fig. 3. Schinus myrtifolia. A-B: Plant in its environment. C: Stems. D: Bark. E: Branch with lenticels. F-G: Leaves. H: Staminate inflorescence. I: Staminate flower. J: Pistillate flower. K: Pistillate inflorescence. L: Branch with fruits. M-N: Fruits. Ñ-O: Cross section of the fruit to the MEB. References: c: resin canal, ed: endocarp, me: mesocarp, s: seed. Scale: C: $1 \mathrm{~m} ; \mathrm{D}: 5 \mathrm{~cm} ; \mathrm{F}-\mathrm{G}: 2 \mathrm{~cm} ; \mathrm{H}, \mathrm{M}-\tilde{\mathrm{N}}: 2 \mathrm{~mm} ; \mathrm{K}: 1 \mathrm{~mm}$. 
levemente anguloso con pubescencia pilosa corta esparcida. Flores pistiladas con sépalos de 1,2-1,3 × 1-1,1 mm, deltoides, ápice redondeado, márgenes ciliados, pubescencia pilosa, corta y rala; pétalos de 1,4-1,5 × 0,9-1 $\mathrm{mm}$, oblongos, ápice redondeado reflexo en el tercio apical, generalmente glabros; disco interestaminal lobulado; estaminodios de 0,4$0,5 \mathrm{~mm}$ long. incluidas las anteras de 0,2-0,25 $\mathrm{mm}$; gineceo de $1-1,4 \times 0,80-1 \mathrm{~mm}$, ovario ovoide, con 3 ramas estilares curvadas más de $90^{\circ}$ de $0,2 \times 0,3 \mathrm{~mm}$ incluidos los estigmas subcapitados; pedicelo no articulado de 2-4,5 mm long., con extremo apical acopado, cortamente piloso. Fruto drupa de 4,9-7,4 $\times$ 5,7-8,2 $\mathrm{mm}$, grosor 2,3-4,5 $\mathrm{mm}$, rojiza con extremos redondeados, lateralmente comprimida, cáliz y pedicelo excéntricos, persistentes; exocarpo friable, rojizo con papilas esparcidas; mesocarpo externamente rugoso, castaño, con conductos resiníferos de 0,22-0,43 mm diám.; endocarpo de 0,05-0,09 $\mathrm{mm}$ con una capa de macroesclereidas y otra de braquiesclereidas en empalizada. Semilla amarilla, fusiforme de 4,06-4,3 × 0,73-0,89 $\mathrm{mm}$.

\section{Nombre vulgar: "Molle".}

Fenología: El inicio de la floración es a comienzo de setiembre en los pies estaminados y a mediados del mismo mes en los pies pistilados. La fructificación comienza en la segunda quincena de octubre y en la primera quincena de noviembre se forman los primeros frutos maduros en la base de los pseudoracimos con flores en la mitad superior. El fin de la fructificación se produce a comienzos de diciembre; en este estadio solo se encuentran frutos maduros en el extremo apical de los pseudoracimos. A partir de allí puede iniciarse una segunda floración y posterior fructificación hasta el mes de marzo. De continuar el tiempo cálido puede producirse una tercera floración $\mathrm{y}$ fructificación excepcional hasta mayo-junio. La caída de hojas se produce en un breve lapso en el invierno con las primeras heladas encontrándose en agosto con hojas nuevas (observación personal en Yacones, Salta, 2018).
Distribución geográfica y ecológica: La bibliografia cita a $S$. myrtifolia para Bolivia y el noroeste de Argentina, en Jujuy y Salta (Barkley, 1957), concordante con Muñoz (2000). Para Silva-Luz (2017) la especie se encuentra en los bosques TucumanoBolivianos, asociados con los bosques de Alnus y Podocarpus, entre 1.400-3.000 m.

En Argentina y en el marco de este trabajo, las poblaciones se encuentran distribuidas en Jujuy y Salta, en la Provincia Biogeográfica de las Yungas en los Distritos de Selva Montana, y por su temperamento heliófilo predominan en el Bosque Montano entre 1.200-2.000 m y en los pastizales de altura o de neblina hasta 2.500-3.200 $\mathrm{m}$ aproximadamente. Con menor frecuencia se encontraron individuos aislados en el Bosque Chaqueño Serrano húmedo del norte del Distrito; también pueden encontrarse a menores altitudes (raro) en proximidades de cursos de agua $500 \mathrm{~m}$ (Fig. 7).

\section{Material estudiado: ARGENTINA. Jujuy:} Dep. Dr. Manuel Belgrano, Yala, quebrada, 1.450 m, 28-I-1940, fr., Schreiter 10875 (LIL); Juan Galán, 18-I-1976, fl.,Cabrera et al. 27342 (SI); Tirax, 17-IX-1981, fl., Rotman 553 (SI); Río de la Cárcel, entre San José de Chijra y Tilquiza, 22-X-1981, fl., Ahumada et al. 4372 (MCNS); Tilquiza, 24-IX-1981, Rotman et al. 564 (SI); Ruta Provincial 29 al Este de León, camino a Tiraxi, zona de puentes, $24^{\circ} 00 \mathrm{~S}$, 6522W, 19-XI-2002, fl., Zuloaga et al. 7859 (MCNS); Dep. El Carmen, Finca Puesto Viejo, camino interno entre Ruta $34 \mathrm{~km} 1171,5 \mathrm{y}$ Santa Rita, sobre el río Lavayén, $20 \mathrm{~km}$ al E de Ruta y $28 \mathrm{~km}$ al $\mathrm{N}$ de la cementera, 480 m, 7-III-2006, fl. fr., Novara et al. 12412 (MCNS). Dep. Ledesma, Ruta provincial 3 camino a Valle Grande, 28-X-1970, fl., Vervoorst \& Cuezzo 7625 (LIL); camino de Ruta 34 a Higueritas, XI-1976, fl., Cabrera et al. 28029 (SI). Dep. Valle Grande, Abra de Cañas, 1.707 m, 2-XII-1969, fr., Legname \& Cuezzo 7261 (LIL). Salta. Dep. Anta, Parque Nacional El Rey, pastizal del cerro Chañar, 20-II-1981, fl., Brown et al. 1675 (MCNS). Dep. Capital, Quebrada de San Lorenzo, 2-XII-1960, fl., Burkart 22046 (SI); Lesser, $1.850 \mathrm{~m}, 16-\mathrm{XI}-1980$, Zapata 43 (MCNS); San Lorenzo, filo de cerros al $\mathrm{W}$ de la quebrada, 
2.000-2.200 m, 29-X-1988, Novara 8164 (MCNS); Yacones, a $2 \mathrm{~km}$ Camping Círculo Médico, después de curva, árbol 4, 14-IX2016, fl., Lozano et al. 560 (MCNS). Dep. La Caldera, Ruta 9 Km 1634,14-XI-1986, Mármol 153 (MCNS); La Angostura, 1.3001.400 m, 29-XI-1981, Novara 2229 (MCNS); La Caldera, 16-XI-1983, Del Castillo \& Varela 139 (MCNS); RN $9 \mathrm{~km} \mathrm{1635,} \mathrm{entrada}$ a Finca La Angostura, 19-IX-2016, fl., Lozano et al. 687 (MCNS); Vaqueros, Serranías de Vaqueros, Arroyo Chaile, 23-VI-2018, Lozano et al. 1362 (MCNS). Dep. Rosario de Lerma, Campo Quijano, Cuenca del río Potrero, 16-II1999, fl., Ortín \& Calzon s.n. (MCNS 1643).

Observaciones: 1- Cuando Grisebach (1879) describió a Cybianthus myrtifolius Griseb. (basónimo de S. myrtifolia), citó por un lado a una colección de "Yacone", sin colector y número de colección. Yacone es una localidad de la provincia de Salta (Argentina) con densas poblaciones de $S$. myrtifolia. Hay una colección de Lorentz \& Hieronymus 317, depositada en GOET, que se recolectó en Yacone en 1873 y se determinó como Cybianthus myrtifolius; probablemente este espécimen es el material original que Grisebach estudió al describir C. myrtifolius. La segunda colección citada fue Balansa 2381, recolectada en Paraguay, donde no habita la especie. El examen de estos especímenes muestra que Lorentz \& Hieronymus 317 es S. myrtifolius. Cuando Cabrera (1937) transfirió Cybianthus myrtifolius a Schinus, no mencionó el material tipo. Posteriormente (1938) citó a Lorentz \& Hieronymus 317 como el tipo; también sinonimizó a $S$. bumelioides con $S$. myrtifolia, y mencionó erróneamente que esta última especie se distribuye en las montañas bajas desde Jujuy hasta Córdoba.

2- En 1957, Barkley corrigió los errores de Cabrera y los propios en Barkley (1944), nombró un Tipo en el Grisebach Herbarium (GOET), un isotipo (CORD00004915) en el material examinado y eliminó la sinonimia con S. bumelioides.

3- En GOET, el Curador Dr. Marc Appelhans, nos informó que se encuentra allí el ejemplar tipo y nos envió una imagen escaneada del mismo, ejemplar GOET020105, en julio 2018, que corresponde efectivamente a Lorentz \& Hieronymus 317. Este es un ejemplar más completo que el depositado en CORD, consistente en dos ramas con variedad de hojas de diferentes formas y tamaños, pseudoracimos sin flores y solo uno con un fruto aparentemente inmaduro alargado, característico de la especie. Por otra parte, el isotipo CORD es un ejemplar muy diferente al disponible en GOET, con ramas muy delgadas terminales y hojas isomorfas espatuladas, pequeñas, casi todas del mismo tamaño, los pseudoracimos sin flores y frutos y una pequeña flor cauliflora solitaria. A pesar de ello no hay dudas que corresponde a $S$. myrtifolia, especie con un notable polimorfismo foliar y también elevada variación en el tipo de ramas.

4- En estudios más recientes de Silva-Luz et al. (2019), se menciona la existencia de muchos problemas en la circunscripción taxonómica, especialmente en ejemplares provenientes de Bolivia que fueron identificados como $S$. andina o $S$. myrtifolia, debido a la existencia de una amplia variación en los caracteres, por lo que según la autora dichos individuos confusamente determinados podrían ser divididos en varias especies.

5- A partir de esta investigación, se concluyó en que los ejemplares de Argentina, coleccionados en Jujuy en las Sierras de Calilegua y hasta Valle Grande, se encontraban mal determinados y confundidos con $S$. venturii.

6- Según la edad de la planta, la forma y el tamaño de las hojas es muy variable y diferente en concordancia o no con la edad de las ramas, a menudo combinándose formas y tamaños. En individuos arborescentes como los de la población estudiada en Yacones, en las ramas de más de tres años, las hojas a menudo son las más pequeñas de 1,3-1,5 $\times$ 0,8-1,2 cm, obovadas, con pecíolo de $2-4 \mathrm{~mm}$ long., subcartáceas. En las ramas de 2-3 años las hojas pueden ser de $2-2,7 \times 1,3-1,5 \mathrm{~cm}$ con pecíolo de 4-5 $\mathrm{mm}$ long., ápice redondeado, a veces retuso o emarginado y base decurrente; también a veces pueden presentarse hojas de mayor tamaño, de 6-7 $\times 2,5-3 \mathrm{~cm}$, coriáceas y elípticas. En las ramas del año las hojas son elípticas y oblongas, de 3,5-4,8 $\times 1,5-2,3 \mathrm{~cm}$ con pecíolo de 5-11 mm long., subcartáceas. Esta relación entre edad de ramas y tipo de 
hojas puede no coincidir en individuos de menor edad.

7- La inflorescencia estaminada de 12-28 $\mathrm{mm}$ long. es más larga que la pistilada de 0,7-10 mm long. La flor pistilada presenta estilo muy corto a nulo y ramas estigmáticas subcapitadas, volcadas sobre el extremo del ovario.

8- Es muy característico de $S$. myrtifolia y sus poblaciones que los individuos adultos porten gran cantidad de agallas esféricas (Fig. 4A-C), que alcanzan hasta $1,2-1,5 \mathrm{~cm}$ de diám., de color verde claro y rojo en el ápice cuando blandas, verde oscuras y de tamaño similar al volverse leñosas, sésiles, esféricas, con opérculo ocre generalmente apical, raro lateral, con tapón, anastomosadas en las ramas de 1-5 años, cubriendo totalmente vastos sectores. Son generadas aparentemente por Cesidoses eremita Curtis (Lepidóptera, Cecidosidae), especie que se encuentra infectando a Schinus fasciculata (Griseb.) I. M. Johnst. en ambientes semiáridos del Espinal en la provincia de Córdoba (Malcolm et al., 2015). Este lepidóptero se reconoce por la forma de las agallas y por la larva oligópoda, blanca, fusiforme, con tres pares de patas y 12 artejos (Fig. 4D-E).

9- La amplia distribución descripta por Muñoz (2000) para la provincia Chaqueña y la Prepuna, no ha sido confirmada en este trabajo.

4. Schinus venturii F. A. Barkley, Brittonia 5(2): 179. 1944. Typus: Bolivia. Bermejo, 27-XI-1903, Fiebrig 2291 (holotypus MO260106!; isotypi F520428!, GH00049192!, MO896886!, NY01043207!, LIL 45269!, S1018379!, SP35576!, S-R10897!, US1472914!) Figs. 5A-M, 6A-D.

Schinus meyeri F. A. Barkley, Lilloa 33 (14): 295. 1973. Typus: Argentina. Salta: Santa Victoria, Los Toldos, Huaico Chico, $1.700 \mathrm{~m}$, 15-VIII-1971, Vervoorst \& Legname 4494 (holotypus LIL!; isotypus GH00049181!). Syn. nov.

Árbol pequeño a arbusto, diclino-dioico, hasta de $5 \mathrm{~m}$ alt. Corteza oscura rugosa. Ramas, estriadas, amarronadas, conlenticelas abultadas regulares de $0,2 \mathrm{~mm}$ diám., semidensas, broncíneas, con pubescencia hírtula corta semidensa y tricomas glandulares, semidensos y broncíneos. Hojas de 5,5-11,8 × 3,2-4,8 cm, ovado-lanceoladas hasta rómbicas, ovadas, elípticas, elíptico-redondeadas, oblongas, generalmente cartáceas, a veces subcartáceas; ápice agudo a veces obtuso o retuso; base ampliamente cuneada, a ligeramente oblicua y decurrente; margen notable de 0,4-1 $\mathrm{mm}$ lat., ocráceo, revoluto, generalmente entero, raro algo crenado en la mitad apical de la lámina; discoloras opacas; con 13-24 pares de nervios secundarios notables e irregulares, nervios de tercer orden perceptibles; haz glabro hasta mínimamente hírtulo, nervio principal con pubescencia semidensa y tricomas glandulares semidensos, esparcidos en la base de la lámina, envés glabro; pecíolo de $7-15 \mathrm{~mm}$, marcadamente canaliculado, hírtulo en el haz, glabro en el envés. Inflorescencias con brácteas de $0,8-1,3 \times 0,6-0,8 \mathrm{~mm}$, deltoides, semicóncavas, nervio medio prominente, ápice agudo o redondeado, pubescencia hírtula en el dorso y ciliada en los márgenes; bractéolas dimórficas, la más pequeña de $0,4-$ $0,5 \times 0,2-0,25 \mathrm{~mm}$, la más grande de $0,6-0,7$ $\times 0,4-0,5 \mathrm{~mm}$, ambas con idéntica forma $\mathrm{y}$ pubescencia que la bráctea. Pseudoracimo estaminado de $11-30 \mathrm{~mm}$ long., raquis anguloso con pubescencia hírtula esparcida. Flores estaminadas con sépalos de $0,6-0,8$ $\times$ 0,7-0,8 mm, deltoides, márgenes ciliados, pubescencia hírtula en haz y envés; pétalos de 1-1,8 × 0,8-1,2 mm, ovados, ligeramente cóncavos, ciliados en el margen, haz hírtulo; disco interestaminal lobulado; androceo con 8 estambres en 2 ciclos de tamaño semejante de 0,9-1 $\mathrm{mm}$ long. incluida la antera, filamentos aplanados y ensanchados hacia la base, anteras de 0,2-0,3 mm long.; pistilodio de 0,3-0,4 $\times$ 0,15-0,2 mm, piriforme, con 3 ramas estilares divergentes; pedicelo no articulado de 2,3$3 \mathrm{~mm}$ long. con extremo apical acopado, pubescencia hírtula semidensa. Pseudoracimo pistilado de 13-30 mm long.; raquis anguloso con pubescencia hírtula. Flores pistiladas con sépalos de 0,8-1 × 0,6-0,8 mm, deltoides, cóncavos, nervio medio prominente, margen ciliado y pubescencia hírtula en el dorso; pétalos de 1,5-2 × 0,5-0,6 mm, oblongos $u$ ovado-oblongos, cóncavos en la mitad superior, 

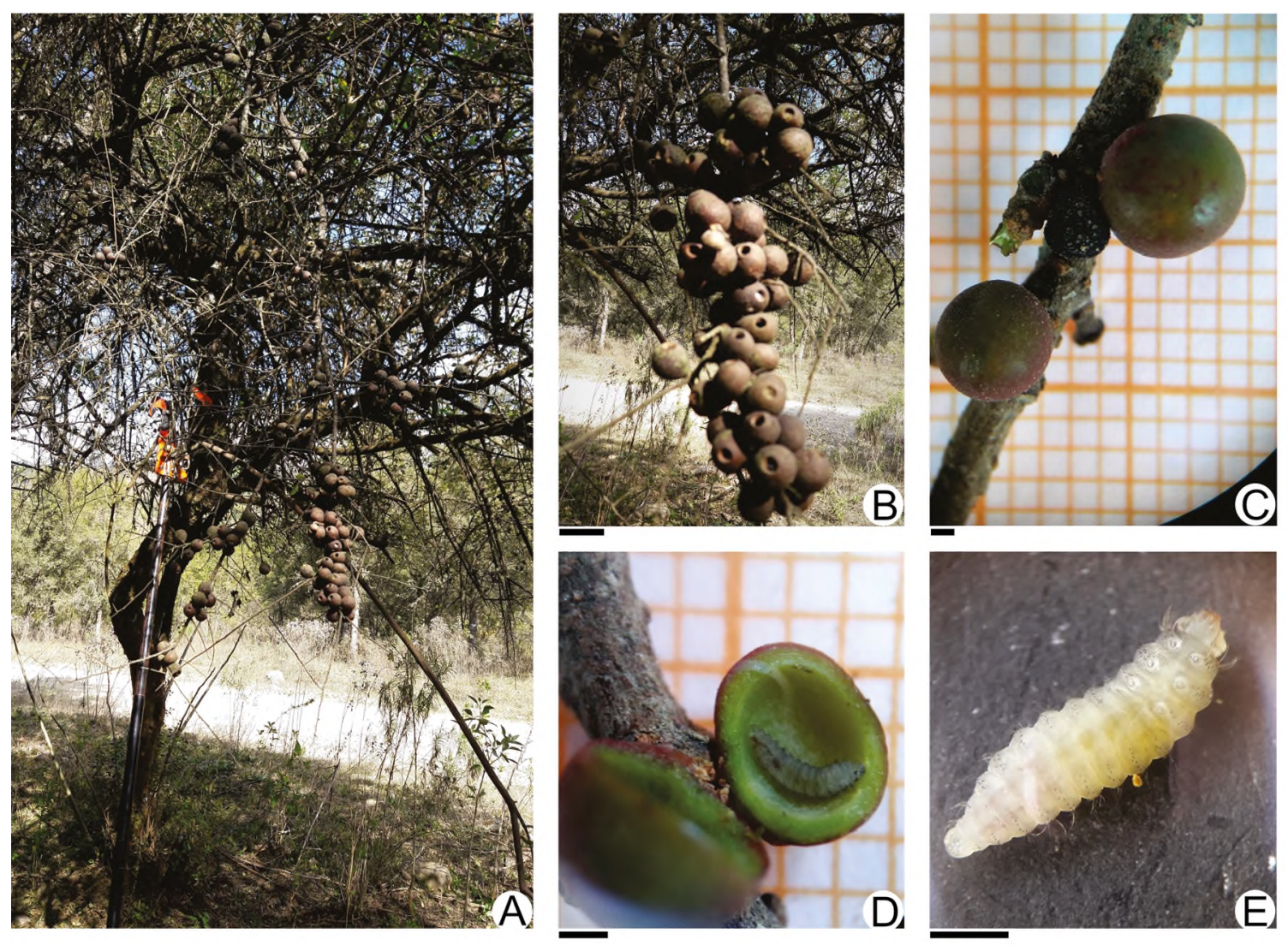

Fig. 4. Schinus myrtifolia. A: Arbusto con agallas lignificadas. B: Rama cubierta por agallas. C: Detalle de dos agallas inmaduras (blandas). D: Corte longitudinal de una agalla con larva. E: Larva. Escala: B: $1 \mathrm{~m}$; C-D: $1 \mathrm{~mm}$; E: 0,5 mm. Fig. 4. Schinus myrtifolia. A: Shrub with lignified galls. B: Branch covered by galls. C: Detail of two immature (soft) gills. D: Longitudinal section of a gill with larva. E: Larva. Scale: B: 1 m; C-D: 1 mm; E: 0.5 mm.

margen ondulado, nervio principal marcado, raro algunos tricomas glandulares en la lámina; disco interestaminal lobulado; estaminodios de 0,3-0,5 mm long. incluidas las anteras de 0,2-0,3 mm long.; gineceo de 1,2- 1,4 × 0,6$0,8 \mathrm{~mm}$, ovario globoso con tricomas cortos, erectos y esparcidos, estilo único muy corto de $0,5 \mathrm{~mm}$ long. y 3 ramas estilares de $0,2-0,3$ mm long. divergentes $90^{\circ}$ del eje principal con estigmas subcapitados de $0,2 \times 0,3 \mathrm{~mm}$ diám.; pedicelos no articulados de 1,5-3,5 $\mathrm{mm}$ long. con extremo apical acopado y pubescencia hírtula semidensa. Fruto drupa de 4,22-6,86 $\times 5,77-7,11 \mathrm{~mm}$, grosor 2,29-3,33 mm, rojiza, ovoidea, lateralmente comprimida, cáliz y pedicelo excéntricos, persistentes; exocarpo friable, rojizo con tricomas en forma de pelos y papilas esparcidas; mesocarpo externamente rugoso, castaño, con conductos resiníferos de 0,6-0,8 mm diám., endocarpo de 0,07-0,1 mm lat. con una capa de macroesclereidas y otra de braquiesclereidas en empalizada. Semilla amarilla, fusiforme de 2-2,7 $\times 0,5 \mathrm{~mm}$.

Nombresvulgares: "Chirimolle", "chirimolle cantarillo".

Fenología: La floración se produce de agosto hasta diciembre y la fructificación ocurre entre octubre y febrero.

Distribución geográfica y ecológica: Habita en el noroeste argentino, en la provincia de Salta (Departamentos Orán y Santa Victoria), también habita en el sur de Bolivia(Dep. Tarija). Las poblaciones de $S$. venturii comprende 

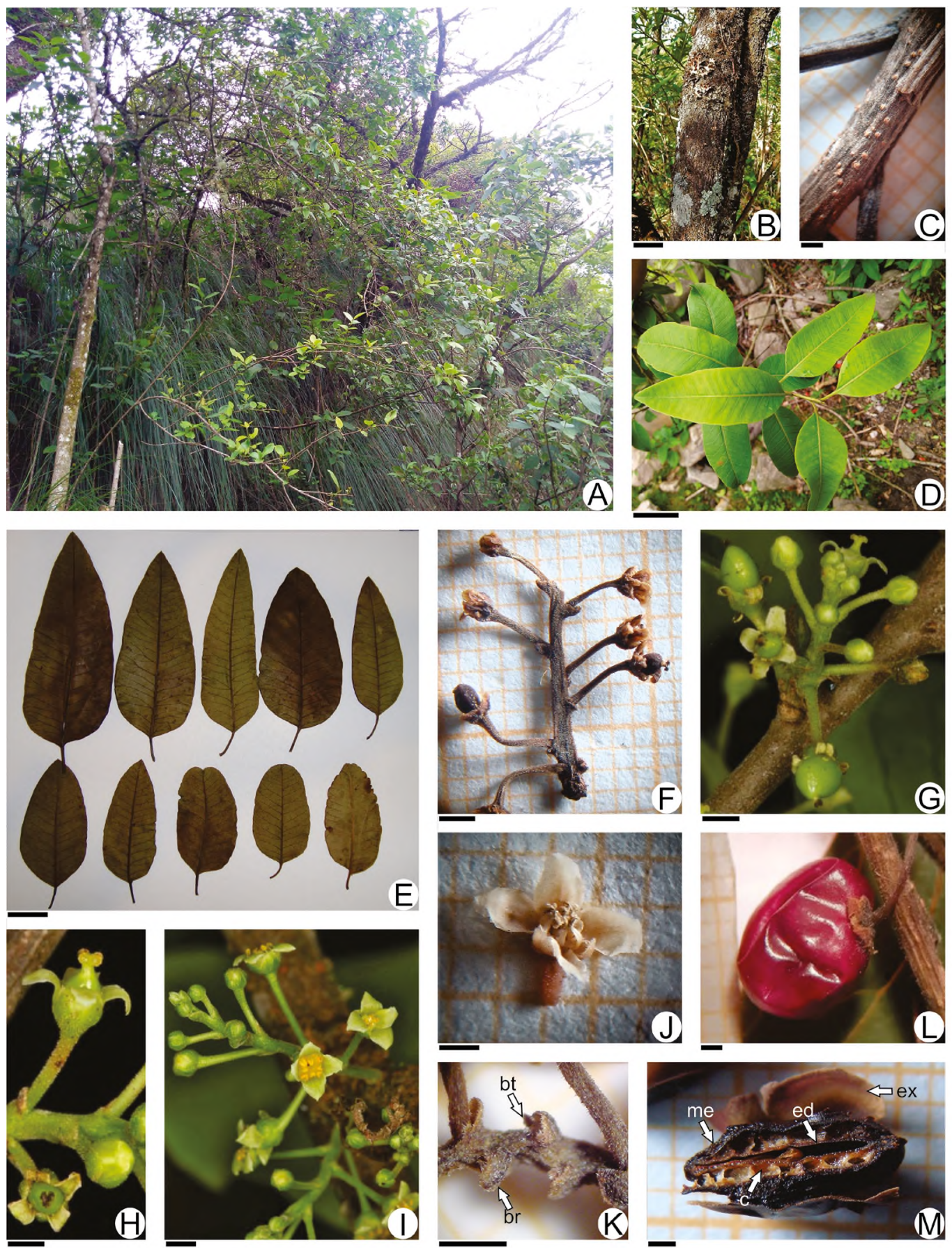

Fig. 5. Schinus venturii. A: Planta en su ambiente. B: Corteza. C: Rama con lenticelas. D-E: Hojas. F-G: Inflorescencia pistilada. H: Flor pistilada. I: Inflorescencia estaminada. J: Flor estaminada. K: Raquis. L: Fruto. M: Corte longitudinal de fruto. Referencias: bt: bractéola, br: bráctea, c: canal resinifero, ed: endocarpo, ex: exocarpo, me: mesocarpo. Escala: B: $10 \mathrm{~cm}$; C: $1 \mathrm{~mm}$; D-E: $2 \mathrm{~cm}$; F-G: $2 \mathrm{~mm}$; H-M: $1 \mathrm{~mm}$.

Fig. 5. Schinus venturii. A: Plant in its environment. B: Bark. C: Branch with lenticels. D-E: Leaves. F-G: Pistillate inflorescence. H: pistillate flower. I: Staminate inflorescence. J: Staminate flower. K: Spines. L: Fruit. M: Longitudinal cut of fruit. References: bt: bractheola, br: bract, c: resin canal, ed: endocarp, ex: exocarp, me: mesocarp. Scale: B: 10 cm; C: 1 mm; D-E: $2 \mathrm{~cm}$; F-G: 2 mm; H-M: 1 mm. 

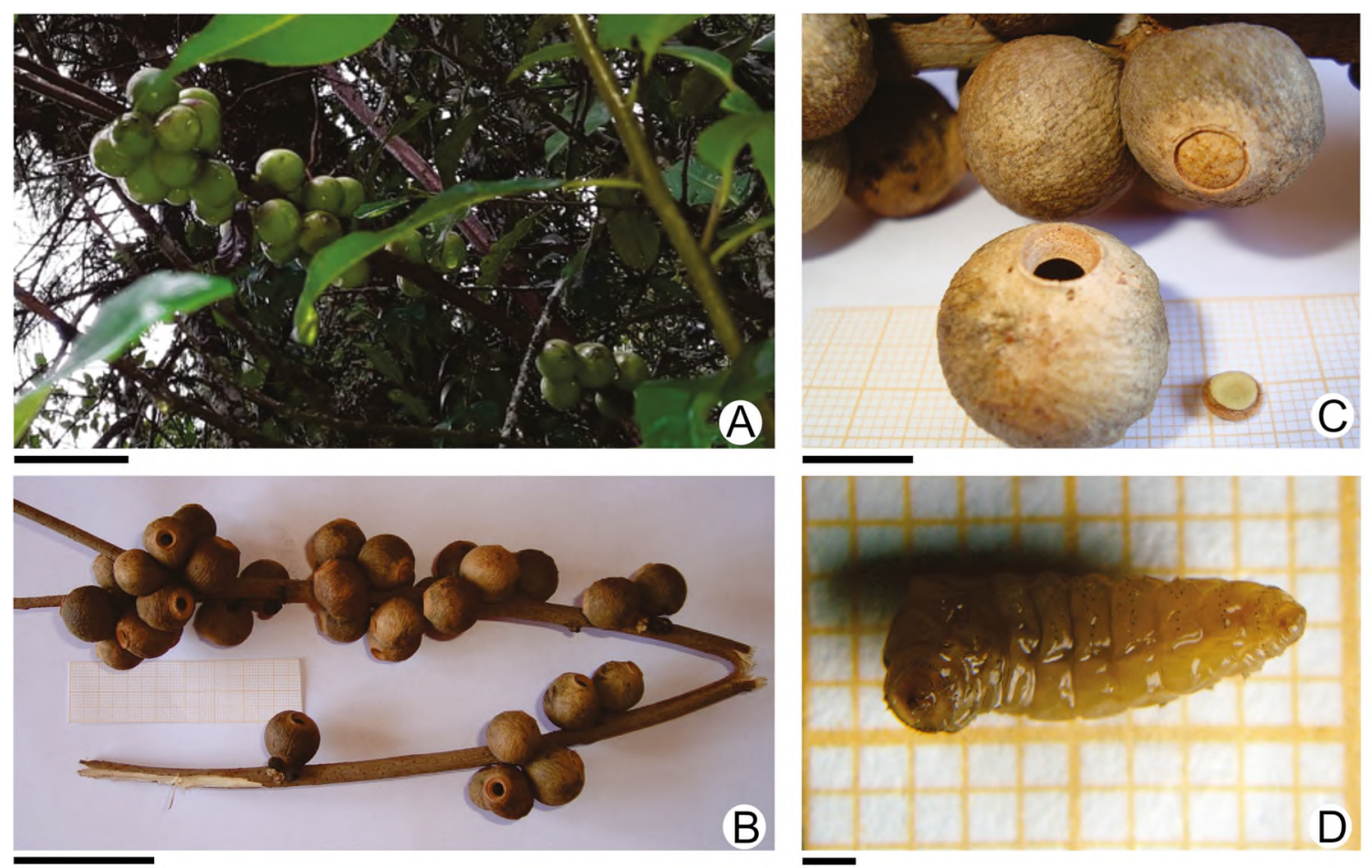

Fig. 6. Schinus venturii. A: Rama con agallas inmaduras (blandas). B: Rama con agallas lignificadas. C: Detalle de agalla y opérculo. D: Larva. Escala: A-B: $5 \mathrm{~cm}$; $: 1 \mathrm{~cm}$; D: $1 \mathrm{~mm}$.

Fig. 6. Schinus venturii. A: Branch with immature (soft) galls. B: Branch with lignified galls. C: Gall and operculum detail. D: Larva. Scale: A-B: $5 \mathrm{~cm}$; $: 1 \mathrm{~cm}$; D: $1 \mathrm{~mm}$.

árboles o arbustos de los bosques montanos de Salta y Bolivia y el ecotono entre los bosques nubosos montanos con los valles interandinos prepuneños, puneños o secos, asociados con los bosques de Podocarpus y Almus (Muñoz, 2000), entre 1.600-1.900 m (Fig. 7).

Material estudiado: ARGENTINA. Salta: Dep. Orán, San Andrés, alrededores del pueblo, 1-XI-2018, fl., Lozano et al. 1432 (MCNS). Dep. Santa Victoria, Los Toldos, entre la Municipalidad y El Arrazay, 1.600 m, 16-III-1986, fl., Novara 5145 (MCNS); Quebrada del Nogalar, 2-5 km W del pueblo, 1.600-1.900 m, 19-III-1986, fr., Novara 5233 (MCNS); PN Baritú, Abra de Minas, I-X-1996, fl., Hilgert 1482 (MCNS); Reserva Nacional El Nogalar, 1.620 m, 29-IV-2010, fr., Del Valle 111 (MCNS); Los Toldos, pueblo, Arroyo Chico, ramas con agallas, 3-I-2020, fr., Lozano et al. 1825 (MCNS).
Observaciones: 1- Analizando los ejemplares tipo de $S$. meyeri y $S$. venturii, además de colecciones propias y preexistentes en herbarios, encontramos que se presenta una importante similitud morfológica entre ambas especies, en forma, tamaño e inclusive consistencia de hojas en un mismo individuo, las que además son muy polimórficas.

2- Se detectaron caracteres que aportan a una sinonimización de $S$. venturii y $S$. meyeri, como el número de nervios de las hojas, el raquis anguloso en la inflorescencia, la pubescencia, el tamaño y la forma de las brácteas como también de las flores y frutos.

3- Las inflorescencias son pseudoracimos congestos tanto estaminados como pistilados cuando incipientes y terminan laxos cuando la mayoría de las flores están en antesis. El término pseudoracimo presente en ésta y otras especies de la sección Myrtifolia se define en este trabajo como el inicio de una ramificación 


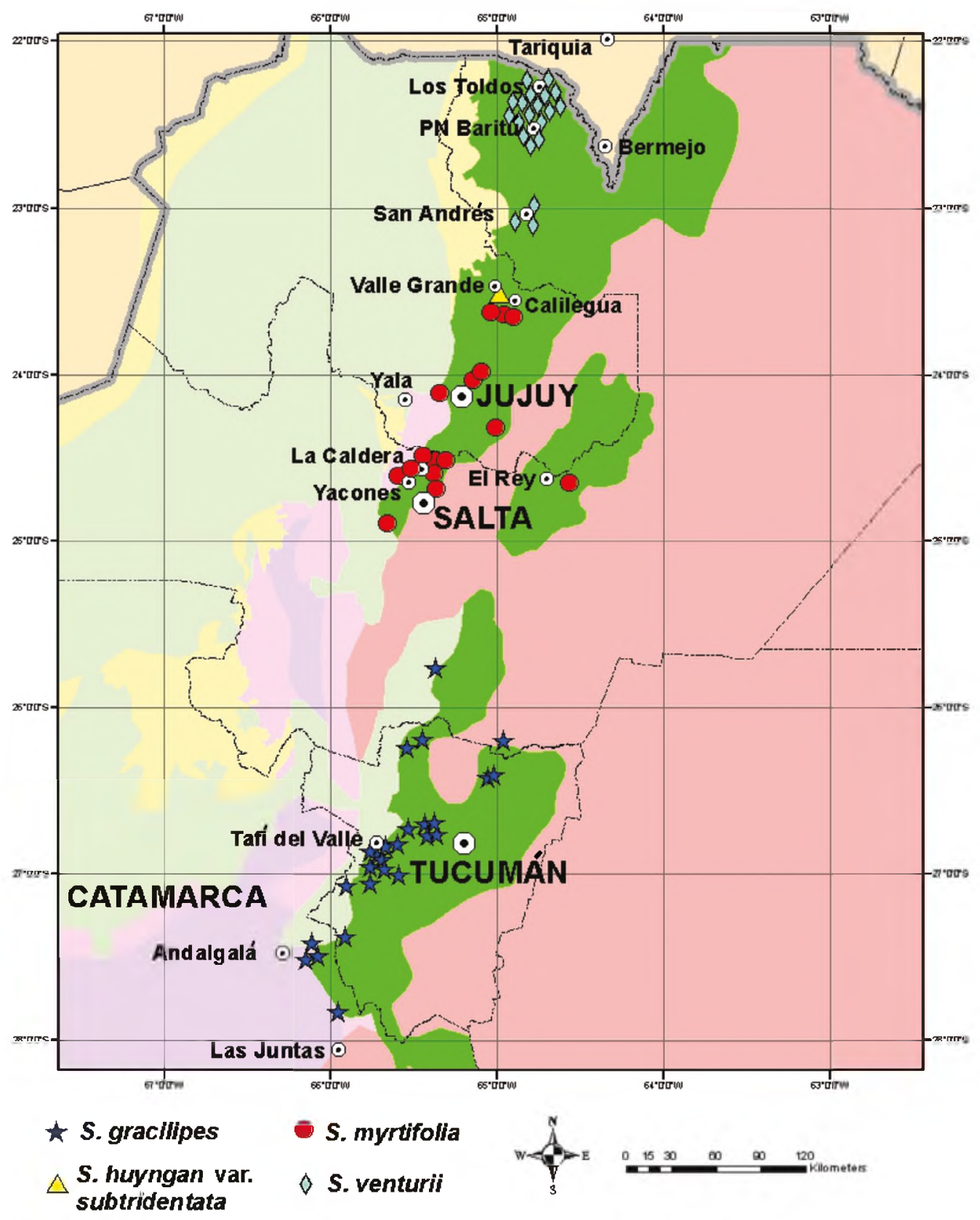

Fig. 7. Distribución geográfica de la sección Myrtifolia del género Schinus en Argentina.

Fig. 7. Geographic distribution of the Myrtifolia section of the genus Schinus in Argentina.

cimosa en un pseudoracimo sin llegar a formar un tirso. Los pétalos se observan con nerviación secundaria del nervio medio visible desde la base en los especímenes de ambas especies. Para los ejemplares argentinos, no se aprecian en este trabajo diferencias excluyentes entre ambas especies.

4- Los individuos adultos de S. venturii portan gran cantidad de agallas esféricas (Fig. 6A-D), que alcanzan hasta $1,3-2,4 \mathrm{~cm}$ de 
diám., de color marrón claro, leñosas, sésiles, esféricas, con opérculo ocre generalmente apical, raro lateral, con tapón, anastomosadas en las ramas, cubriendo totalmente vastos sectores. Son generadas aparentemente por Cesidoses eremita especie que también infecta a Schinus myrtifolia.

5- Se observa una incongruencia en la tarjeta del ejemplar tipo de S. venturii, Fiebrig 2291, Bolivia, donde se menciona que la colección fue realizada en Bermejo a $1.000 \mathrm{~m}$, teniendo en cuenta que la localidad de Bermejo se encuentra a los $419 \mathrm{~m}$ en el límite BoliviaArgentina. Se infiere que el registro de la tarjeta, no alude a la localidad de Bermejo sino al Río Bermejo que bordea la ruta RN 45 a Tarija en su mayor trayecto hasta la latitud de Los Toldos donde el sector serrano-montañoso en el que habita $S$. venturii avanza del oeste y llega hasta la ruta, por lo que podría haber sido el real sitio de colecta del ejemplar tipo.

6- También se encontraron ejemplares de herbario de $S$. venturii confundidos (mal determinados) como $S$. gracilipes.

\section{Clave para la identificación de las especies de Schinus sección Myrtifolia de Argentina}

A. Inflorescencia pseudoracimo. Hojas polimórficas, margen entero o irregularmente crenado hasta la base. Flores con pedicelo articulado o no articulado.

B. Ramas subagudas, pubescencia glandular. Hojas obovadas, raro elípticas, coriáceas, margen apical crenado con 3-5 lóbulos regulares. Pedicelo articulado. .......................... huyngan var. subtridentata

B'. Ramas normales, pubescentes y con tricomas glandulares. Hojas polimórficas, membranáceas y cartáceas, margen generalmente entero. Pedicelo no articulado.

C. Hojas de 0,8-2,5 cm lat., cartáceas a la madurez, con 5-12 pares de nervios. Lenticelas grandes de $0,5 \mathrm{~mm}$ diám. Pétalos glabros. S. myrtifolia

$C^{\prime}$. Hojas de 3,2-4,8 cm lat., subcartáceas, con 13-24 pares de nervios secundarios paralelos.

Lenticelas pequeñas de $0,2 \mathrm{~mm}$ diám. Pétalos hírtulos en el envés con margen ciliado. .. S. venturii

A'. Inflorescencia tirsoide con cimas dicasiales. Hojas ovadas u ovado-lanceoladas, margen siempre crenado o crenado-aserrado en los $2 / 3$ apicales. Pedicelo articulado S. gracilipes

\section{Discusión}

Respecto a la inflorescencia de $S$. gracilipes, ha sido definida por Juárez de Varela et Novara (2007) como una panícula y por Digilio et Legname (1966) como un racimo de cimas trifloras. En esta investigación, en base a todos los ejemplares estudiados, se definió a la inflorescencia de $S$. gracilipes como un tirsoide, constituido por un raquis con generalmente tres flores en cada nudo (dicasios), a veces más flores pediceladas por nudo en la axila de una bráctea, protegidas cada flor por dos bractéolas, con sentido de floración acrótona.

La inflorescencia en S. myrtifolia para Barkley (1957), es un pseudoracimo con pedicelos florales articulados. En otro análisis realizado por Silva-Luz (2017) menciona inflorescencias generalmente en pseudoracimos o tirsoides ramificados, raramente panículas. En esta investigación, en base a todos los ejemplares estudiados, se definió a la inflorescencia de $S$. myrtifolia como un pseudoracimo, constituido por un raquis con una sola flor pedicelada por nudo en la axila de una bráctea y dos bractéolas, sin pedicelo articulado y con sentido de floración acrótona.

Con respecto a $S$. venturii, Muñoz (2000) menciona que posee hojas agudas u obtusas, enteras o algo crenadas, con pecíolos esparcidamente pubérulos, éstos de 0,4-0,7 cm. La diferencia que señala con $S$. meyeri es que 
sus hojas son generalmente agudas, enteras, a veces ligeramente crenadas, pubérulas sobre los márgenes de la base de la lámina, el nervio central y a veces los pecíolos, estos de 0,7-1,5 cm. Los caracteres analizados como diferenciales por Muñoz son únicamente vegetativos de hojas (lámina y pecíolos) los que resultan confusos porque se solapan en casi todos los aspectos considerados, inclusive el pecíolo.

Para Silva-Luz (2017) S. meyeri posee hojas subcartáceas, raramente cartáceas; venas terciarias conspicuas; inflorescencias estaminadas esencialmente pseudoracimos laxos y pétalos con nervio medio que a menudo se ramifica desde la porción mediana hacia el ápice, y la diferencia de $S$. venturii por sus hojas cartáceas; venas terciarias discretas; inflorescencias estaminadas pseudoracimos esencialmente congestos y pétalos con nervio medio que a veces se ramifica solo en el ápice. Sin embargo, observamos que las poblaciones atribuidas a las dos especies presentan hojas cartáceas en estado adulto, las venas terciarias son visibles en las láminas de ambas, respecto a la pubescencia se la observa hírtula, no pubérula.

\section{Conclusiones}

En este trabajo y de acuerdo a la clasificación infragenérica postulada por Silva-Luz (2017) y Silva-Luz et al. (2019) el género Schinus sección Myrtifolia en Argentina comprende a: $S$. gracilipes, $S$. huyngan var. subtridentata, $S$. myrtifolia y $S$. venturii. Se sinonimizaron $S$. gracilipes var. pilosa y $S$. meyeri.

Schinus gracilipes es claramente diferenciable de las restantes especies de la sección por sus hojas completamente crenadas; inflorescencia tirsoides con cimas dicasiales y pedicelo articulado. Su hábitat, típicamente yungueño y restringido a la parte superior de la selva montana en ecotono con el bosque montano, en el bosque montano y en los pastizales de neblina, tiene la distribución más austral y altitudinal de la sección, en Tucumán y Catamarca.
Schinus huyngan var. subtridentata es el primer registro para Argentina en las Yungas de Jujuy, en la zona de Calilegua, con una sola colección vista, donde podría compartir hábitat con $S$. myrtifolia de la que se diferencia por el porte, el sistema de ramificación, la forma, tamaño de las hojas y flores con el pedicelo articulado.

Schinus myrtifolia es otra especie con alto polimorfismo foliar poblacional, acorde con la edad de las ramas y una marcada helicomorfía. Este polimorfismo foliar condujo a que la especie fuera confundida con otras de la sección como $S$. venturii y $\mathrm{S}$. gracilipes, por la forma y tamaño de hojas, también por la crenación del margen. Tiene una distribución central en el área de distribución de la sección Myrtifolia en Argentina, en el centro-este de Salta y sur de Jujuy. A veces puede encontrarse respecto a las otras especies de la sección a menor altitud y en ambientes más xéricos.

Schinus venturii es la especie con el mayor polimorfismo foliar en un mismo individuo, inclusive en una rama, lo que se puede observar claramente en las colecciones de herbario. También es la especie con la distribución más septentrional en Argentina.

Las cuatro especies se distribuyen en Argentina de norte a sur ocupando diferentes franjas latitudinales.

\section{Agradecimientos}

Al Consejo de Investigación de la Universidad Nacional de Salta, Proyecto de Investigación Tipo A $\mathrm{N}^{\mathrm{o}} 2383$, en cuyo marco se financió la realización de este trabajo.

A los Sres. Curadores de herbarios visitados como el Dr. Massimiliano Dematteis (CTES), la Dra. Nora Muruaga (LIL) y la Dra. Olga Martínez (MCNS), por su atención durante los días de trabajo en sus instituciones. También a Curadores de herbarios nacionales: CORD, Dra. Gloria Barboza; SI, Dr. Manuel Belgrano y extranjero GOET, Dr. Marc Appelhans, quienes brindaron imágenes de material tipo y respondieron nuestras consultas. A los estudiantes colaboradores del proyecto, Emanuel Fuentes, José Gabriel Benci y Gustavo Araya. 


\section{Bibliografía}

Barkley, F. A. (1944). Schinus L. Brittonia 5: 160198.

Barkiey, F. A. (1957). A study of Schinus L. Lilloa 28: 4-109.

BARKLEY, F. A. (1973). Schimus meyeri. Una nueva especie de Anacardiaceas. Lilloa 33: 295-297.

CABrera, A. L. (1937). Schinus myrtifolia (Griseb.) Cabrera. Obra del Cincuentenario del Museo de La Plata 2: 269

Cabrera, A. L. (1938). Revisión de las Anacardiáceas Austroamericanas. Revista del Museo de La Plata, Botánica 2: 3-64.

Cabrera, A. L. \& Willink, A. (1980). Biogeografía de América Latina. 2da. Edición. Monografías de la OEA, Serie de Biología, Washington, DC.

Digilio, A. P. \& Legname P. R. (1966). Los árboles indígenas de Tucumán. Opera Lilloana 15: 1-107.

Fabbroni, M. \& Zapater CANo, M. A. (2021). Novedades en el género Schinus (Anacardiaceae): delimitación de Schinus polygama y descripción de una nueva especie, Schinus talampaya. Boletín de la Sociedad Argentina de Botánica 56: 1-16. https://doi.org/10.31055/1851.2372.v56.n2.31297

JSTOR. (2021). JSTOR Global Plants. Disponible: https:// plants.jstor.org/collection/ (consulta 06/08/2021).

Juárez De Varela, F. \& Novara L. J. (2007). Anacardiaceae Lindl. En Novara, L. J. (ed.), Aportes Botánicos de Salta, Ser. Flora 8: 1-27.

Macbride, J. F. (1951). Anacardiaceae. En MacbrdDe, J. F. (ed.), Flora of Perú, Publications of the Field Columbian Museum, Botanical series 13: 238-258.
Malcom, M., Oggero, A. J.,Arana, M. D., Tordable, M. DEL C. \& BoITo, G. T. (2015). Los insectos galícolas en Schinus fasciculata (Anacardiaceae) en el Espinal del centro de Argentina. Theringia, Serie Zoología 105: 133-139. https://doi.org/10.1590/1678-476620151051133139

MuÑoz, J. D. (2000). Anacardiaceae. En HunZIKER, A.T. (ed.), Flora Fanerogámica Argentina 65: 1-28.

Perea, M. C., Pedraza, G. \& Luceros, J. (2007). Relevamiento de la flora arbórea autóctona en la provincia de Catamarca. San Fernando del Valle de Catamarca, Catamarca. 1ra. ed. Ed. Consejo Federal de Inversiones.

Silva-Luz, C. L. DA. (2017). Filogenia e sistemática de Schinus L. (Anacardiaceae), com revisão de um clado endêmico das matas nebulares andinas. Tesis Doctoral. Instituto de Biociências da Universidade de São Paulo, Brasil. 176 pp.

Sinva-Luz, C. L. Da, Pirant, J. R., Mitchell, J. D., Daly, D., Capelli, N. do V., Demarco, D., Pell, S. K. \& Plunkett, G. M. (2019). Phylogeny of Schimus L. (Anacardiaceae) with a new infrageneric classification and insights into evolution of spinescence and floral traits. Molecular Phylogenetics and Evolution 133: 302-351.

https://doi.org/10.1016/j.ympev.2018.10.013

THIERS, B. (2021) Index Herbariorum: a global directory of public herbaria and associated staff. New York Botanical Garden's Virtual Herbarium, http:// sweetgum.nybg.org/science/ih (Consulta 26/1 1/2021).

Tropicos. (2021). Tropicos.org. MissouriBotanical Garden. Disponible: http://www.tropicos.org (Consulta 06/08/ 2021). 